\title{
Inverse relationship between nonadherence to original GOLD treatment guidelines and exacerbations of COPD
}

This article was published in the following Dove Press journal:

International Journal of COPD

6 January 2017

Number of times this article has been viewed

\author{
Hussein D Foda ${ }^{1,2}$ \\ Anthony Brehm ${ }^{1,2}$ \\ Karen Goldsteen ${ }^{3}$ \\ Norman H Edelman ${ }^{2,4}$ \\ 'Division of Pulmonary Critical Care \\ and Sleep Medicine, Department of \\ Medicine, Veterans Affairs Medical \\ Center, Northport, ${ }^{2}$ Division of \\ Pulmonary Critical Care and Sleep \\ Medicine, Department of Medicine, \\ Stony Brook University Medical \\ Center, Stony Brook, NY, ${ }^{3}$ MPH \\ Program, University of North \\ Dakota School of Medicine and \\ Health Sciences, Grand Forks, ND, \\ ${ }^{4}$ Department of Preventative Medicine \\ and Program in Public Health, Stony \\ Brook University Medical Center, \\ Stony Brook, NY, USA
}

Background: Prescriber disagreement is among the reasons for poor adherence to COPD treatment guidelines; it is yet not clear whether this leads to adverse outcomes. We tested whether undertreatment according to the original Global Initiative for Chronic Obstructive Lung Disease (GOLD) guidelines led to increased exacerbations.

Methods: Records of 878 patients with spirometrically confirmed COPD who were followed from 2005 to 2010 at one Veterans Administration (VA) Medical Center were analyzed. Analysis of variance was performed to assess differences in exacerbation rates between severity groups. Logistic regression analysis was performed to assess the relationship between noncompliance with guidelines and exacerbation rates.

Findings: About 19\% were appropriately treated by guidelines; $14 \%$ overtreated, $44 \%$ undertreated, and in $23 \%$ treatment did not follow any guideline. Logistic regression revealed a strong inverse relationship between undertreatment and exacerbation rate when severity of obstruction was held constant. Exacerbations per year by GOLD stage were significantly different from each other: mild 0.15 , moderate 0.27 , severe 0.38 , very severe 0.72 , and substantially fewer than previously reported.

Interpretation: The guidelines were largely not followed. Undertreatment predominated but, contrary to expectations, was associated with fewer exacerbations. Thus, clinicians were likely advancing therapy primarily based upon exacerbation rates as was subsequently recommended in revised GOLD and other more recent guidelines. In retrospect, a substantial lack of prescriber adherence to treatment guidelines may have been a signal that they required re-evaluation. This is likely to be a general principle regarding therapeutic guidelines. The identification of fewer exacerbations in this cohort than has been generally reported probably reflects the comprehensive nature of the VA system, which is more likely to identify relatively asymptomatic (ie, nonexacerbating) COPD patients. Accordingly, these rates may better reflect those in the general population. In addition, the lower rates may reflect the more complete preventive care provided by the VA.

Keywords: COPD exacerbations, COPD treatment guidelines, COPD in US Veterans Affairs Medical Centers

\section{Introduction}

Adherence to evidence-based therapeutic guidelines is often poor. Previous studies have identified multiple causes, which are related to patients' behavior and their environment. However unfamiliarity with, and in some cases, significant disagreement with the guidelines on the part of practitioners were also found to be the causes of nonadherence. ${ }^{1}$ With regard to COPD, a recent review ${ }^{2}$ affirms these findings and indicates that the clinical significance of the lack of practitioner adherence to treatment
Correspondence: Norman H Edelman Department of Preventive Medicine and Program in Public Health, Stony Brook University Medical Center, HSC L3, R094, Stony Brook, NY I I794, USA $\mathrm{Tel}+$ I 63| 3798870

Email norman.edelman@stonybrook.edu
International Journal of COPD 2017:12 209-214

(c) (1) (2) ( ) 2017 Foda et al. This work is published and licensed by Dove Medical Press Limited. The full terms of this license are available at https:///www.dovepress.com/terms.php

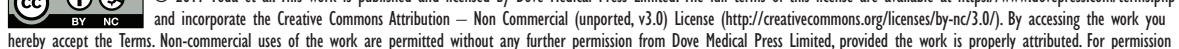

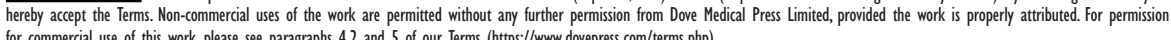


guidelines is currently unclear. This study was done to determine whether the lack of adherence by prescribers to established guidelines for the management of COPD resulted in poorer outcomes as measured by exacerbation rates. We used the 2004 update of the original Global Initiative for Chronic Obstructive Lung Disease (GOLD) guidelines, ${ }^{3}$ which were summarized by Rabe et al, ${ }^{4}$ which advanced treatment based upon the degree of airway obstruction, because they were the best established at the point of time we chose to examine in order to "follow" patients for multiple years and because they were the ones recommended by the Veterans Administration (VA) at that time. The unexpected key finding described herein is that patients who were undertreated by the original GOLD guidelines had fewer rather than more exacerbations as was originally hypothesized.

\section{Methods}

\section{Patient data}

This study was approved by the Institutional Review Boards at the Northport VA Medical Center and Stony Brook University. As the retrospective data were de-identified prior to analysis individual informed consent was also not necessary according to these Institutional Review Boards. Subjects were initially identified by utilizing ICD-9 codes for COPD. Patients were included in the analysis, if they met the GOLD spirometric criteria for COPD prior to $1 / 1 / 2005$ and continued to be cared for at the VA until 12/31/2010 or until they die. We utilized the post bronchodilator $\mathrm{FEV}_{1} / \mathrm{FVC}$ ratio and the $\mathrm{FEV}_{1}$ from the most recent spirometry on or before $12 / 31 / 2006$ to diagnose COPD and to separate the patients into severity subgroups as defined by the original GOLD criteria. We defined appropriateness of therapy based upon GOLD recommendations for each severity subgroup of COPD (Table 1). If patients were prescribed medications that were recommended for a disease severity category more severe than the one they were classified as being overtreated. If they were prescribed therapy based upon the severity category less severe than their own classification they were considered to be undertreated. If they were prescribed therapy not recommended for any stage, they were considered to have been incorrectly treated. Patients were considered to have suffered an exacerbation if they had an emergency room visit, hospitalization, or outpatient visit for respiratory symptoms that was accompanied by the addition of systemic steroids, and/or an antibiotic to their regimen. Death was also defined as an exacerbation.

\section{Statistical analysis}

Differences in exacerbation rates for each of the GOLD severity categories were tested for significance by the analysis of variance. Multivariate logistic regression analysis was applied to investigate which characteristics were associated with an increased rate of exacerbations as compared to the group with the mildest GOLD stage. We included the following covariates entered in the following order: GOLD stage of COPD, treatment group (correctly treated, undertreated, overtreated, and incorrectly treated), smoking status, and age in $1 / 1 / 2005$.

\section{Results Demographics}

Demographic data are shown in Table 2 and are similar to those in other studies, except for gender distribution. The distribution of the patients according to GOLD severity groups was also similar to other studies. ${ }^{5}$ Over the follow-up period, 278 (31.7\%) patients died. Eighteen (20.9\%) patients were with mild COPD, 101 (26.6\%) with moderate COPD,

Table I GOLD severity stage of COPD and recommended therapies based on 2004 GOLD recommendations

\begin{tabular}{|c|c|c|}
\hline COPD severity stage & Spirometric criteria FEV,/FVC $<\mathbf{7 0 \%}$ & Recommended therapies \\
\hline Stage I (mild) & $\mathrm{FEV}_{1} \geq 80 \%$ predicted & As needed short-acting $\beta$ agonists \\
\hline Stage II (moderate) & $80 \%>\mathrm{FEV}_{1} \geq 50 \%$ & $\begin{array}{l}\text { As needed short-acting } \beta \text { agonists } \\
\text { Add regular treatment with one or more long-acting } \\
\text { bronchodilators }\end{array}$ \\
\hline Stage III (severe) & $50 \%>\mathrm{FEV}_{1} \geq 30 \%$ & $\begin{array}{l}\text { As needed short-acting } \beta \text { agonists } \\
\text { Regular treatment with one or more long-acting bronchodilators } \\
\text { Add inhaled corticosteroids if repeated exacerbations }\end{array}$ \\
\hline Stage III (very severe) & $30 \%>\mathrm{FEV}$, or $<50 \%$ and chronic respiratory failure & $\begin{array}{l}\text { As needed short-acting } \beta \text { agonists } \\
\text { Regular treatment with one or more long-acting bronchodilators } \\
\text { Inhaled corticosteroids if repeated exacerbations } \\
\text { Add long-term oxygen therapy } \\
\text { Consider surgical treatments }\end{array}$ \\
\hline
\end{tabular}

Notes: The 2004 updated COPD guideline advocated a stepwise incremental approach to treating COPD based on a patients' GOLD severity stage. Abbreviations: COPD, chronic obstructive pulmonary disease; GOLD, Global Initiative for Chronic Obstructive Lung Disease. 
Table 2 Demographic variables

\begin{tabular}{ll}
\hline Variable & Number (\% of total) \\
\hline Age (years) & \\
$49-64$ & $128(14.6)$ \\
$65-74$ & $203(23.2)$ \\
$75-84$ & $330(37.7)$ \\
$\geq 85$ & $214(24.5)$ \\
Race & \\
$\quad$ Caucasian & $837(95.3)$ \\
Non-Caucasian & $41(4.7)$ \\
Gender & $869(99)$ \\
Male & $9(1)$ \\
Female & \\
COPD severity & $86(9.8)$ \\
Mild (FEV , $\geq 80 \%)$ & $379(43.2)$ \\
Moderate (FEV, 50\%-80\%) & $292(33.3)$ \\
Severe (FEV, 30\%-50\%) & $121(13.8)$ \\
Very severe (FEV, $\leq 30 \%)$ &
\end{tabular}

Abbreviation: COPD, chronic obstructive pulmonary disease.

99 (33.9\%) with severe COPD, and 60 (49.6\%) with very severe COPD.

\section{Adherence of treatment regimen to GOLD guidelines}

As seen in Table 3, the treatment regimen followed the 2001 GOLD guidelines in $34.9 \%$ of patients with mild COPD, $5.0 \%$ of patients with moderate COPD, $25.0 \%$ of patients with severe COPD, and $34.7 \%$ of patients with very severe COPD. In patients where the treatment regimen did not comply with guidelines most were undertreated $(44.0 \%$ of the total). Additionally, $23.1 \%$ patients received treatment not consistent with any of the guidelines' recommendations irrespective of disease severity.

\section{Rate of exacerbations}

Exacerbation rates are shown by GOLD category in Table 4 . The rates in each category are significantly different from each other $(P<0.05)$ and increase with increasing severity of obstruction. Of note, is that these rates are substantially lower than those reported in a meta-analysis of the literature ${ }^{6}$ for each GOLD category. Table 5 shows the results of multivariate logistic regression analysis listing variables tested against exacerbation rate. Mild COPD was the variable held constant. As expected, the positive beta value between exacerbation rate and severity of airway obstruction indicated more frequent exacerbations with increasing severity. With severity held constant, there was no residual effect of age or smoking status. In addition, and most notably, there was a strong negative relationship between undertreatment and exacerbation rate. That is, the fewer exacerbations a patient had, the more likely he was being undertreated by the original GOLD guidelines.

\section{Discussion}

This study was done to characterize the management of COPD in an academic VA facility in the middle of the last decade in relation to clinical guidelines, which were prominent at that time. That is, well after the initial GOLD guidelines had been disseminated but well before the more recent emphasis of guidelines on the rate of exacerbations as separate determinants of therapeutic strategy. ${ }^{7}$ There are two major findings. First, the rates of exacerbations in all GOLD classes were substantially less than that found in previous studies, although the level of obstruction remained a determinant of exacerbation rate, as previously shown. ${ }^{6}$ Second, $44 \%$ were considered to have been undertreated by GOLD recommendations, while only $33 \%$ were categorized as having been appropriate or overtreated. However, there was a very strong inverse correlation between undertreatment and exacerbation rate. That is, undertreatment predicted fewer exacerbations. Thus, the data strongly suggest that clinicians were using exacerbation rate as an important determinant of therapy; the fewer exacerbations the less aggressive the therapy despite severity of obstruction by spirometric criteria. It may be noted at this point that therapeutic guidelines subsequently promulgated by other entities generally suggest less aggressive pharmacologic treatment than those of the original GOLD guidelines. ${ }^{8,9}$

\section{Methodological considerations}

The patient population was similar to others studied with COPD such as that reported by Hurst et al, except for the

Table 3 Compliance of therapy with the 20I I GOLD recommendations by stage

\begin{tabular}{llllll}
\hline $\begin{array}{l}\text { Therapy according } \\
\text { to GOLD }\end{array}$ & $\begin{array}{l}\text { GOLD stage I, } \\
\%(\text { mild) }\end{array}$ & $\begin{array}{l}\text { GOLD stage II, } \\
\%(\text { moderate) }\end{array}$ & $\begin{array}{l}\text { GOLD stage III, } \\
\%(\text { severe) }\end{array}$ & $\begin{array}{l}\text { GOLD stage IV, } \\
\% \text { (very severe) }\end{array}$ \\
\hline Appropriate & $34.9(30)$ & $5.0(19)$ & $25.0(73)$ & $34.7(42)$ & $\begin{array}{l}\text { Total, \% } \\
\text { Overtreated }\end{array}$ \\
Undertreated & $37.2(32)$ & $24.5(93)$ & $0.0(0)$ & $0.0(0)$ & $18.7(164)$ \\
Incorrect & $15 . I(13)$ & $43.8(166)$ & $55.5(162)$ & $37.2(45)$ & $44.2(125)$ \\
\hline
\end{tabular}

Note: Bracketed numbers reflect absolute number of patients.

Abbreviation: GOLD, Global Initiative for Chronic Obstructive Lung Disease. 
Table 4 Exacerbation rate by original GOLD stage

\begin{tabular}{ll}
\hline COPD stage & Exacerbation rate, events/year \\
\hline Mild & 0.149 \\
Moderate & 0.272 \\
Severe & 0.380 \\
Very severe & 0.719 \\
Total & 0.358 \\
\hline
\end{tabular}

Abbreviations: COPD, chronic obstructive pulmonary disease; GOLD, global initiative for chronic obstructive lung disease.

virtual absence of females in the current study. ${ }^{5}$ Since in the Hurst et al's study, females had fewer exacerbations than males, the relatively low exacerbation rate in the current cohort is even more notable. The strength of our study was that all were patients at the VA facility who carried the diagnosis and met the GOLD definition of COPD and for whom adequate data were available over a specified time period were included. This is likely to be a much more inclusive cohort than, for example, the data summarized in the 2011 GOLD report, ${ }^{7}$ which relies heavily on data from pharmaceutical trials that ordinarily exclude many patients as unsuitable for study.

A critical issue is the way in which we enumerated "exacerbations". Our study was greatly facilitated by the existence of the VA electronic medical record. Thus, we did not have to rely on the varying judgments of individual prescribers, but could apply standard criteria retrospectively. We attempted to be inclusive and any hospital admission, emergency room, or outpatient encounter for a respiratory problem in which antibiotics or systemic steroids were prescribed was considered as an exacerbation. A potential confounder is the possibility that patients sought care outside the VA system for an exacerbation without informing their

Table 5 Logistic regression analysis of exacerbation rate

\begin{tabular}{llll}
\hline Independent variable & Beta value & $\boldsymbol{t}$-Value & $P$-value \\
\hline Mild COPD (constant) & & & \\
$\quad$ COPD very severe & 0.230 & 4.622 & 0.000 \\
COPD severe & 0.196 & 3.259 & 0.001 \\
$\quad$ COPD moderate & 0.118 & 1.971 & 0.049 \\
Undertreated & -0.179 & -3.759 & 0.000 \\
Overtreated & 0.039 & 0.871 & 0.384 \\
Incorrect treatment & -0.055 & -1.231 & 0.219 \\
Smoker & 0.042 & 1.198 & 0.231 \\
Age & -0.047 & -1.348 & 0.178 \\
\hline
\end{tabular}

Notes: The dependent variable is exacerbation rate per year. Independent variables are as listed. The beta coefficient indicates the strength and direction of the relationship of the independent variable to exacerbation rate holding the other independent variables constant. The $t$ - and $P$-values refer to the significance of the beta coefficient.

Abbreviation: COPD, chronic obstructive pulmonary disease.
VA providers of care. It is not likely that this happened with any significant frequency, as for financial reasons, most VA patients receive their medications at the VA and report any "outside" exacerbations when doing so. The medications received during such an exacerbation would be reconciled in the VA medical record.

Respiratory failure and heart failure interact and are mutually reinforcing when COPD patients die often making it difficult to ascertain which the initiating event was. Accordingly, we chose what we considered to be a conservative approach and recorded all deaths as COPD exacerbations. We do not believe that whatever uncertainties may have been introduced by this approach could have negated our two basic inferences. We reason as follows: first, we showed that the rates of exacerbation in each GOLD class were lower than that of previously reported. Excluding "true" cardiac deaths would have further reduced these rates. Second, we showed an inverse relationship between nonadherence to GOLD guidelines and exacerbation rates. Failure to exclude "true" cardiac deaths might have affected this interpretation in the GOLD stage IV patients as they had the highest rates for death and exacerbations, as previously shown. However, adherence to the guidelines in this stage was at a high level relative to other stages. Thus in order for the inclusion of cardiac deaths to have biased the findings in the observed direction there would have to have been relatively more of these in relation to respiratory deaths in this stage. This seems rather unlikely as the severity of the COPD in stage IV would have predisposed to just the opposite, that is, relatively greater respiratory deaths.

\section{Exacerbations}

Both analyses showed that GOLD class predicted exacerbation rate, confirming the findings of previous studies. ${ }^{5,10}$ Thus, even in this population, with a substantially lower overall rate of exacerbations than other populations, classification by spirometric criteria remained a significant predictor of this clinical outcome. Of note, this association remained robust in multifactor logistic regression analysis controlling for age and smoking.

It is not entirely clear why the exacerbation rates were lower than those reported in other studies. Methodological issues are considered above. It is possible that despite our attempt to be inclusive, the objective criteria we used to identify exacerbations may have been more stringent than those used by Hoogendoom et $\mathrm{al}^{6}$ in their meta-analysis, although we attempted to use the symptom-based definition they used. A more likely cause relates to the generally agreed upon fact 
that the underdiagnosis of COPD is substantial and that it is most prevalent among patients who have the fewest acute symptoms; that is, exacerbations. ${ }^{2}$ It is highly likely that the VA system identifies far more such individuals than general health care systems as a result of the comprehensiveness of its care model and its favorable cost structure to patients. ${ }^{11}$ This would lead to an overall lower exacerbation rate. Accordingly, it seems reasonable to posit that the exacerbation rates reported herein are more reflective of rates in the general COPD population, both diagnosed and undiagnosed, than in previous reports. Buttressing this argument is a recent study from Labonte et al, evaluating the burden of undiagnosed COPD on the Canadian health care system. In their cohort, the majority of patients with COPD remain undiagnosed and have fewer symptoms and clinical impairment than patients diagnosed with COPD. ${ }^{12}$ However, we do note that important preventive services, such as flu and pneumonia vaccinations, are achieved at much higher rates in the VA system than in the general population. ${ }^{13}$ Additionally, there are generally fewer barriers to care for comorbid conditions, such as congestive heart failure. ${ }^{14}$ Thus, we must consider that there may also be a true lower rate of COPD exacerbations in a VA setting as compared to community settings.

\section{Therapeutic decisions}

Table 3 shows that most patients could not be categorized as being treated appropriately according to the original GOLD recommendation. Undertreatment was the greatest deviation, almost $50 \%$ in the moderate and severe categories. As would be expected, overtreatment was confined to the mild and moderate categories. A significant number of treatments were simply found to be "incorrect" by the GOLD criteria. Some of these, such as the prescription of both short- and long-acting anticholinergic medications, were truly incorrect. The remainder included treatments, such as theophylline only or oral prednisone only.

A robust association in our regression analyses was the negative one between undertreatment by the original GOLD guidelines and exacerbations. On the basis of the extensive previous studies, it is not at all likely that "appropriate" or "over" treatment increased exacerbations. ${ }^{15}$ Rather, the most likely cause of this association is that clinicians based treatment upon exacerbation rate to a greater extent and to a lesser extent, or perhaps not at all, upon spirometric findings. Thus, the findings of Hurst et al, ${ }^{5}$ the updated recommendations of the 2011 GOLD report, ${ }^{7}$ and the recommendations of other more recently established guidelines ${ }^{8,9,16}$ suggest that clinicians were practicing the "art" of medicine to reach appropriate therapeutic decisions despite existent guidelines in the mid-2000s, that is, prior to the accumulation of scientific evidence in support of their approaches. This observation may be generalized to suggest that the substantial lack of adherence to therapeutic guidelines by knowledgeable prescribers may be a signal to re-evaluate such guidelines.

\section{Conclusion}

In this retrospective study of $878 \mathrm{VA}$ patients with COPD, we related the severity of obstruction and adherence to treatment guidelines, both according to original GOLD criteria, to the outcome of exacerbation and/or death over a 5-year period in the middle of the last decade. There were four major findings. 1) In fewer than $20 \%$ of patients were the treatment judged to be appropriate by the established (ie, original) GOLD guidelines, with the majority of treatment deviations in the undertreatment category. 2) However, contrary to expectations, undertreatment was associated with fewer exacerbations. This strongly suggests that prescribers were advancing therapy based upon the frequency of exacerbations, rather than spirometric measurements, before frequent exacerbations were recognized as a separate phenotype and incorporated into the revised GOLD and other guidelines. These considerations may be generalized to suggest that high levels of prescriber noncompliance may be a signal to re-evaluate established therapeutic guidelines. 3) Rates of exacerbation were significantly lower in this cohort than previously reported for more general populations with the equivalent levels of severity of obstruction. This may reflect the benefits of the more comprehensive VA care model by greater identification of COPD patients with few or no exacerbations and by more complete preventive services and comorbid condition care. 4) Rates of exacerbation paralleled the severity of obstruction by spirometric criteria, as previously shown.

\section{Acknowledgment}

Funded by a Novartis investigator initiated research grant. This material is the result of work supported with resources and the use of facilities at the Veterans Affairs Medical Center, Northport, New York, where HDF is Chief of Medicine. The contents do not represent the views of the US Department of Veterans Affairs or the United States Government.

\section{Disclosure}

The authors report no conflicts of interest in this work. 


\section{References}

1. Make B, Dutro MP, Paulose-Ram R, Marton JP, Mapel DW. Undertreatment of COPD: a retrospective analysis of US managed care and Medicare patients. Int J Chron Obstruct Pulmon Dis. 2012;7:1-9.

2. Han MK, Martinez CH, Au DH, et al. Meeting the challenge of COPD care delivery in the USA: a multiprovider perspective. Lancet Respir Med. 2016;4(6):473-526.

3. Pauwels RA, Buist AS, Calverley PM, Jenkins CR, Hurd SS, Committee GS. Global strategy for the diagnosis, management, and prevention of chronic obstructive pulmonary disease. NHLBI/WHO Global Initiative for Chronic Obstructive Lung Disease (GOLD) workshop summary. Am J Respir Crit Care Med. 2001;163(5):1256-1276.

4. Rabe KF, Hurd S, Anzueto A, et al. Global strategy for the diagnosis, management, and prevention of chronic obstructive pulmonary disease: GOLD executive summary. Am J Respir Crit Care Med. 2007;176(6):532-555.

5. Hurst JR, Vestbo J, Anzueto A, et al. Susceptibility to exacerbation in chronic obstructive pulmonary disease. N Engl J Med. 2010;363(12):1128-1138.

6. Hoogendoorn M, Feenstra TL, Hoogenveen RT, Al M, Molken MR. Association between lung function and exacerbation frequency in patients with COPD. Int J Chron Obstruct Pulmon Dis. 2010;5:435-444.

7. Vestbo J, Hurd SS, Agusti AG, et al. Global strategy for the diagnosis, management, and prevention of chronic obstructive pulmonary disease: GOLD executive summary. Am J Respir Crit Care Med. 2013;187(4): 347-365.

8. Qaseem A, Wilt TJ, Weinberger SE, et al. Diagnosis and management of stable chronic obstructive pulmonary disease: a clinical practice guideline update from the American College of Physicians, American College of Chest Physicians, American Thoracic Society, and European Respiratory Society. Ann Intern Med. 2011;155(3):179-191.
9. NICE guidelines [CG101]. Chronic obstructive pulmonary disease in over 16s: diagnosis and management. London: National Institute for Health and Care Excellence; 2010. Available from: nice.org.uk/ guidance/cg101. Accessed August 9, 2016.

10. Faganello MM, Tanni SE, Sanchez FF, Pelegrino NR, Lucheta PA, Godoy I. BODE index and GOLD staging as predictors of 1-year exacerbation risk in chronic obstructive pulmonary disease. Am J Med Sci. 2010; 339(1):10-14.

11. Asch SM, McGlynn EA, Hogan MM, et al. Comparison of quality of care for patients in the Veterans Health Administration and patients in a national sample. Ann Intern Med. 2004;141(12):938-945.

12. Labonte LE, Tan WC, Li PZ, et al. Undiagnosed chronic obstructive pulmonary disease contributes to the burden of health care use. Data from the CanCOLD study. Am J Respir Crit Care Med. 2016;194(3): 285-298.

13. Jha AK, Perlin JB, Steinman MA, Peabody JW, Ayanian JZ. Quality of ambulatory care for women and men in the Veterans Affairs Health Care System. J Gene Int Med. 2005;20(8):762-765.

14. Chokshi DA. Improving health care for veterans - a watershed moment for the VA. N Engl J Med. 2014;371(4):297-299.

15. White P, Thornton H, Pinnock H, Georgopoulou S, Booth HP. Overtreatment of COPD with inhaled corticosteroids - implications for safety and costs: cross-sectional observational study. PLoS One. 2013; 8(10): 75221.

16. Rennard S, Thomashow B, Crapo J, et al. Introducing the COPD foundation guide for diagnosis and management of COPD, recommendations of the COPD foundation. COPD. 2013;10(3):378-389.
International Journal of COPD

\section{Publish your work in this journal}

The International Journal of COPD is an international, peer-reviewed journal of therapeutics and pharmacology focusing on concise rapid reporting of clinical studies and reviews in COPD. Special focus is given to the pathophysiological processes underlying the disease, intervention programs, patient focused education, and self management protocols.

\section{Dovepress}

This journal is indexed on PubMed Central, MedLine and CAS. The manuscript management system is completely online and includes a very quick and fair peer-review system, which is all easy to use. Visit $\mathrm{http} / / / \mathrm{www}$.dovepress.com/testimonials.php to read real quotes from published authors. 